\title{
Atom Probe Tomography: A Characterization Method for Three-dimensional Elemental Mapping at the Atomic Scale
}

\author{
Pyuck-Pa Choi* and Ivan Povstugar \\ Max-Planck-Institut für Eisenforschung, Department of Microstructure Physics and Alloy Design, \\ Max-Planck-Str.1, 40237 Düsseldorf, Germany \\ (Received January 17, 2012; Revised February 1, 2012; Accepted February 10, 2012)
}

\begin{abstract}
The present paper gives an overview about the Atom Probe Tomography technique and its application to powder materials. The preparation of needle-shaped Atom Probe specimens from a single powder particle using focusedion-beam milling is described. Selected experimental data on mechanically alloyed (and sintered) powder materials are presented, giving insight into the atomic-scale elemental redistribution occurring under powder metallurgical processing.
\end{abstract}

Keywords: Atom probe tomography, Characterization, Focused-ion-beam, Mechanical alloying

\section{Introduction}

In the past of couple decades, Atom Probe Tomography (APT) has emerged as one of the most promising nano-analytical techniques [1-3]. APT is based on the controlled field evaporation of atoms from the surface of a sharp, needle-shaped sample and is a combination of ion projection microscopy and time-of-mass spectrometry. Due to its capability of giving three-dimensional data with near atomic resolution, APT is a powerful tool for studying phase transformations at or below the nanometer-scale, solute segregation and/or partitioning at internal interfaces as well as nanostructure-property relationships [1-3]. Recently, APT has also been successfully applied to mechanically alloyed powder materials [4-8], giving insights into the distribution of alloying and impurity elements. The present paper gives an overview about the APT technique and its application to powder materials.

\section{Experimental}

\subsection{Principles of atom probe tomography (APT)}

Fig. 1. illustrates the principles of APT taken from Ref. [1].

For an APT analysis a sharp needle-shaped sample having a typical radius of curvature of $100 \mathrm{~nm}$ or below, is required. By applying a high positive base voltage to the specimen and superposing either ultra-fast voltage or laser pulses to the base voltage, controlled field-evaporation of ions from the specimen surface is induced. The field-evaporated ions are accelerated by the electric field towards a position sensitive detector that records their time-of -flight and impact positions. The mass-to-charge ratio is determined from the potential energy $n e V$ of the escaping ion, where $V$ is the applied voltage between the specimen and the counter electrode. At the entrance of the counter electrode, the potential energy is fully converted into the kinetic energy is $1 / 2 m v^{2}$. The ion velocity, $v$, is approximately $d / t$ ( $d$ : distance between specimen and detector, $t$ : time-of-flight) under the assumption that the final velocity of a field evaporated ion is reached shortly after its removal from the tip surface. Then the mass-tocharge ratio $\mathrm{m} / \mathrm{n}$ can be derived from a simple energy balance equation

$$
\frac{m}{n}=\frac{2 e}{d^{2}}\left(V_{D C}+a V_{p}\right) t^{2}
$$

where $V_{D C}$ and $V_{P}$ are the standing and pulse voltages applied to the specimen and $\alpha$ is a pulse amplitude coupling factor to account for some loss in the effectiveness of the pulse.

A three-dimensional elemental map can be reconstructed

*Corresponding Author : P. P. Choi, TEL: +49-211-6792-167, FAX: +49-211-6792-333, E-mail: p.choi@mpie.de 


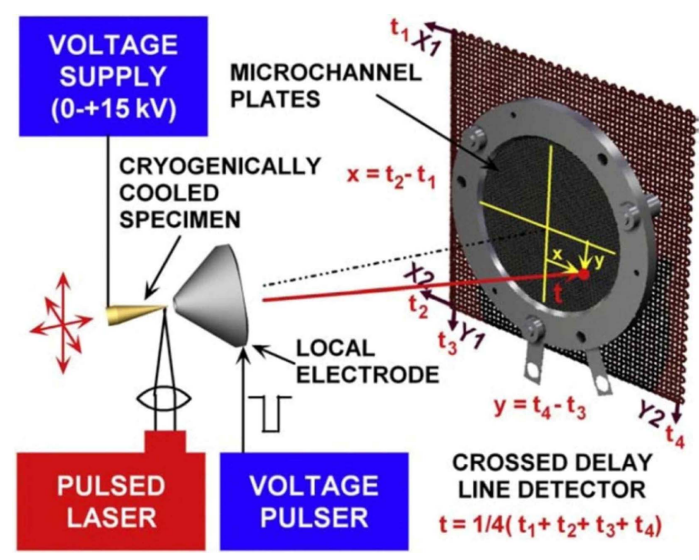

Fig. 1. Schematic of APT taken from Ref. [1].

from the collected data, using an inverse point projection algorithm. Typical dimensions of the analyzed volume are $50 \times 50 \times 200 \mathrm{~nm}^{3}$ for state-of-the-art instruments (e.g. a Local Electrode Atom Probe (LEAP) as shown in Fig. 1). The resolution limits are about $\Delta x=\Delta y=0.2 \mathrm{~nm}$ and $\Delta \mathrm{z}=0.1 \mathrm{~nm}$. Impurity levels as low as $10 \mathrm{ppm}$ can be traced. Therefore, APT is a powerful tool for studying the elemental distribution in nanostructured materials.

\subsection{Preparation of APT specimens from powder} materials using focused-ion-beam milling

The preparation of needle-shaped APT specimens from powder materials is a challenge and it is essential that efficient and generally applicable techniques are developed. The usage of focused ion-beam (FIB) milling for the preparation of APT specimens has attracted great interest for the past decade, particularly for materials which cannot be electropolished and for site-specific specimen preparation [9]. Fig. 2 and 3 present a way of preparing APT specimens from a single powder particle, as the author previously reported [4].

In the first step, a protective Pt layer is deposited on the center of a selected particle (see Fig. 2(a)). Deep sloped, staircase-shaped trenches are milled next to the Pt layer (Fig. 2(b)), leaving behind a lamella of $\sim 20 \mu \mathrm{m} \times$
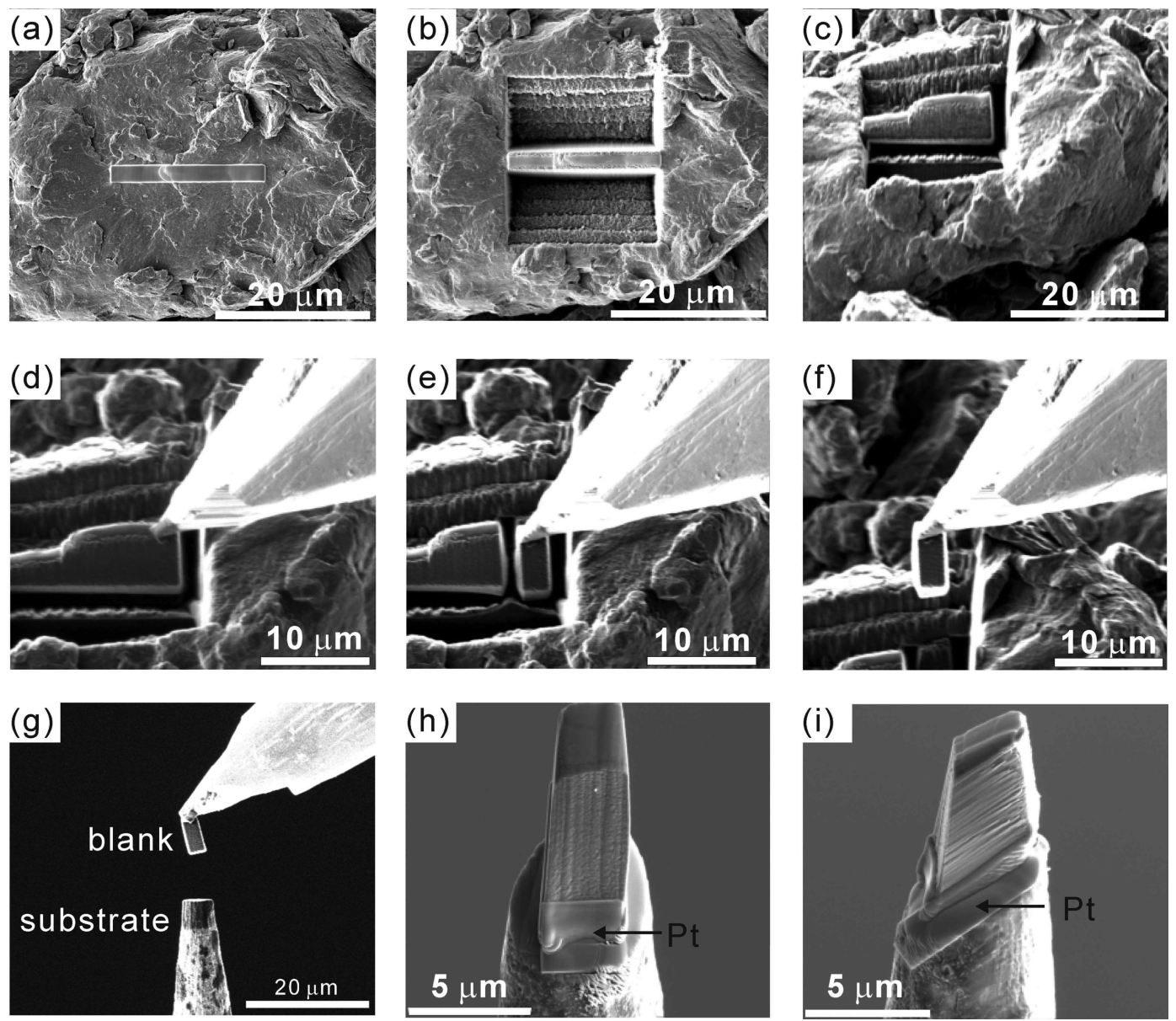

Fig. 2. FIB-based in situ lift-out method for APT specimen preparation from a single powder particle: (a)-(f): lift-out of a square cross-sectional blank $\sim 2 \mu \mathrm{m} \times 2 \mu \mathrm{m} \times 5 \mu \mathrm{m}$ in size; (g)-(i): attachment to a W substrate (taken from Ref. [4]). 

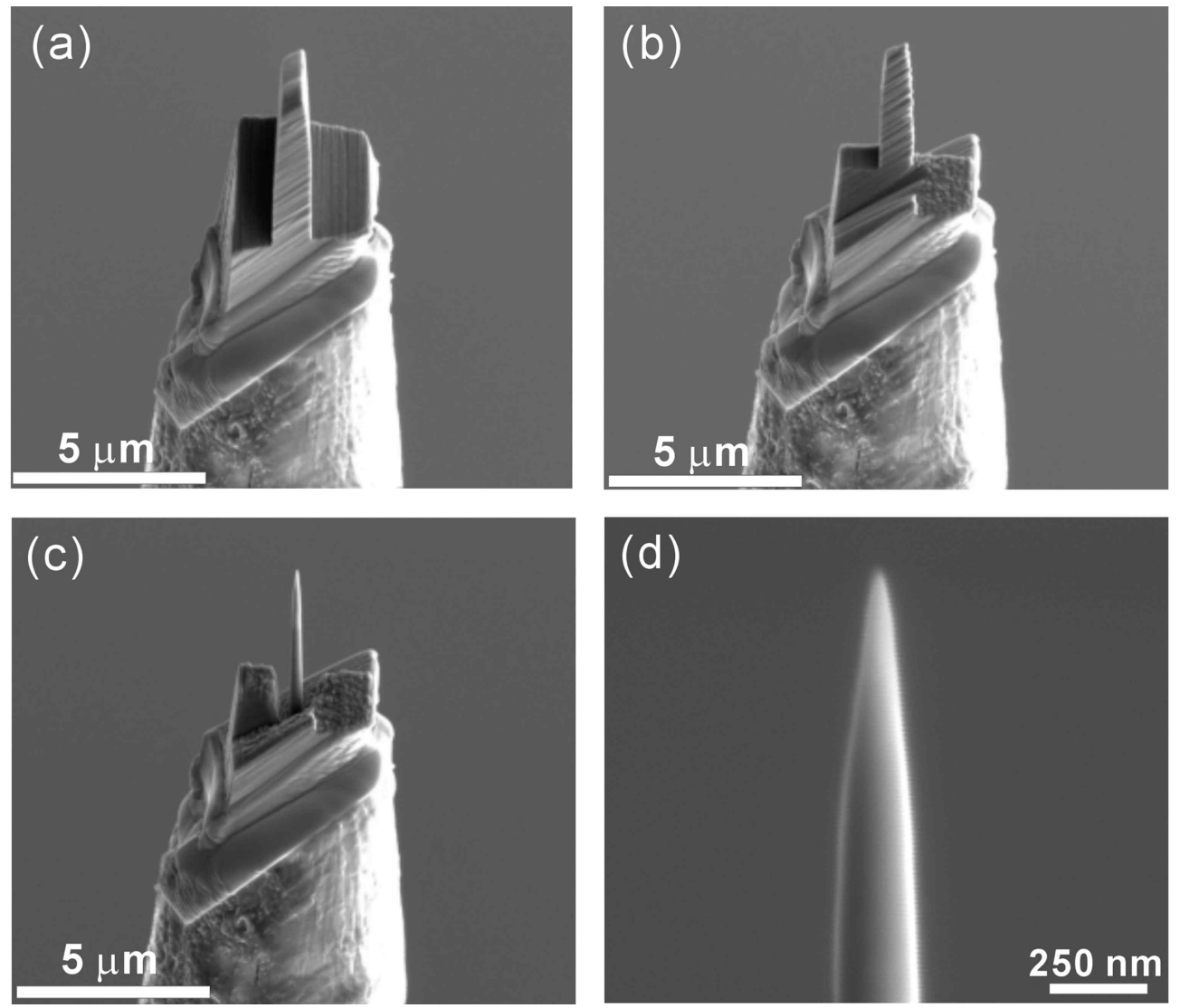

Fig. 3. Ion-milling sequence, forming a post from the upper half of a blank using rectangular milling patterns followed by annular milling (taken from Ref. [4]).

$10 \mu \mathrm{m} \times 2 \mu \mathrm{m}$ in dimension. After tilting the sample $52^{\circ}$ relative to the ion beam column, two line cuts are made through the lamella in an "L" shape (Fig. 2(c)). Subsequently, a sharp needle probe is introduced into the chamber and attached to the edge of the lamella by $\mathrm{Pt}$ deposition (Fig. 2(d). A cross-sectional blank ( $\sim 2 \mu \mathrm{m} \times$ $2 \mu \mathrm{m} \times 5 \mu \mathrm{m}$ in size) is lifted out and positioned on a W support tip (see Fig. 2(e)-(g)). The blank is attached to the substrate by depositing Pt on each side of the blank/substrate interface after $90^{\circ}$ rotation (see Fig. 2(h)-(i)).

Fig. 3(a)-(d) shows the ion-milling sequence of a blank. As only the upper half of the blank is ion milled, the specimen preparation time can be substantially reduced. The dimensions and number of undesired protrusions, which may occur due to undercutting the shank, is small. In case a protrusion is created besides the actual tip, it can be simply removed in a separate step. Annular milling is continued until the tip has a radius of curvature smaller than 100 $\mathrm{nm}$ (Fig. 3(d)). The total specimen preparation time, including the lift-out, was about $3 \mathrm{~h}$ in this case.

\section{Application of APT to Powder Materials and Compacts}

Due to the recent developments in instrumentation as well as sample preparation techniques, APT becomes increasingly important not only for the analysis of bulk materials such as cast steels but also for investigations of local chemistry of powders or sintered compacts. Some illustrative examples exhibiting the strength and unique capabilities of atom probe in application to those classes of materials are presented below.

Fig. 4 presents the results of APT investigations of mechanical alloying in the immiscible binary Fe-Mg system. The mixture of high-purity elemental powders of Fe-7at.\% Mg composition forms a $\alpha-\mathrm{Fe}(\mathrm{Mg})$ supersaturated solid solution under mechanical alloying in a planetary ball mill. The alloying process is completed after 16 $\mathrm{h}$ of milling according to the data obtained from X-ray diffraction and Moessbauer spectroscopy [10]. APT analysis confirms that $\mathrm{Fe}$ and $\mathrm{Mg}$ are strongly mixed by that 


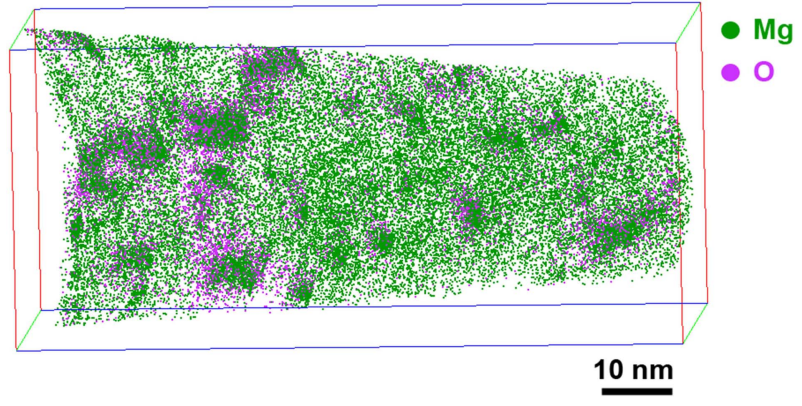

Fig. 4. APT atom map of mechanically alloyed Fe-7at.\% Mg (Pulverizette-7, $16 \mathrm{~h}$ ). Inhomogeneous distribution of $\mathrm{Mg}$ in the solid solution as well as clustering of oxygen atoms is clearly visible.

milling time. However, the $\mathrm{Mg}$ distribution remains not fully homogeneous. Mg-enriched areas of 2-10 nm in size are clearly seen in the APT atom map, with the Mg concentration up to five times higher compared to its average content. Another important issue for the $\mathrm{Fe}-\mathrm{Mg}$ system is the distribution of oxygen which originates from the oxide layer in initial $\mathrm{Mg}$ powder and, therefore, inevitably contaminates the alloyed powder. APT shows that oxygen atoms are located near the areas of $\mathrm{Mg}$ enrichment but are almost absent in the regions with relatively low $\mathrm{Mg}$ concentration. A more detailed look reveals that oxygen-rich zones form "envelopes" around Mg-rich ones, spreading about $2 \mathrm{~nm}$ around. Thus, APT results clearly demonstrate that atomic mixing is not complete, i.e. homogeneous solute distributions either cannot be reached in the mechanically alloyed material or takes much longer milling times to achieve it.

Another APT study of mechanical alloying in and immiscible system was performed by Wille et al. for the case of $\mathrm{Fe}-\mathrm{Cu}$ binary mixture [11]. It was shown that fully homogeneous $\mathrm{Cu}$ distribution can be achieved after $10 \mathrm{~h}$ of ball milling in the system with $\mathrm{Cu}$ content of 2.5 at.\%. As the equilibrium solubility of $\mathrm{Cu}$ in $\mathrm{Fe}$ is negligible at room temperature, the resulting solid solution is strongly supersaturated. When the $\mathrm{Cu}$ concentration rises up to $10 \mathrm{at} \%, \mathrm{Cu}$, complete mixing of $\mathrm{Fe}$ and $\mathrm{Cu}$ cannot be reached by mechanical alloying, although the results of other techniques such as X-ray diffraction suggest that mechanical alloying process has completed. The obtained elemental distributions in such model systems are useful for the theoretical understanding of deformation-induced mass transport occurring under mechanochemical synthesis.
Brocq et al. characterized the oxide dispersion strengthened (ODS) Fe-14Cr-2W-1Ti-0.8Y-0.2O (wt.\%) steel elaborated by reactive ball milling without using $\mathrm{Y}_{2} \mathrm{O}_{3}$ as a starting material [12]. A new mechanism of formation of homogeneously distributed oxygen-containing nanoclusters, which are of $1 \mathrm{~nm}$ in size and strongly enriched with titanium and yttrium, was observed in the alloy.

Williams et al. performed APT studies of nanoscale features in the multicomponent ODS-Eurofer 97 steel prepared by ball milling of metallic powder ingot with $\mathrm{Y}_{2} \mathrm{O}_{3}$ powder with consequent hot isostatic pressing [13]. An alignment of nanometer-sized yttria-based along lath/ twin boundaries was detected. The concentration, shape and composition of clusters were quantitavely characterized. A core-shell structure of clusters was found, where the core consists predominantly of $\mathrm{Y}$ and $\mathrm{O}$ while the shell is enriched in $\mathrm{V} / \mathrm{Cr}$ (see Fig. 5).

Bulk nanocomposite $\mathrm{SmCo} / \mathrm{Fe}$ permanent magnets prepared by ball milling and warm compaction were investigated by Xiong et al. [14]. A microstructure consisting of nanometer-sized iron particles uniformly distributed in SmCo matrix was detected. It was found that $\alpha$-Fe particles contain about 26 at.\% Co (see Fig. 6). Such a particle composition shows a higher saturation magnetization
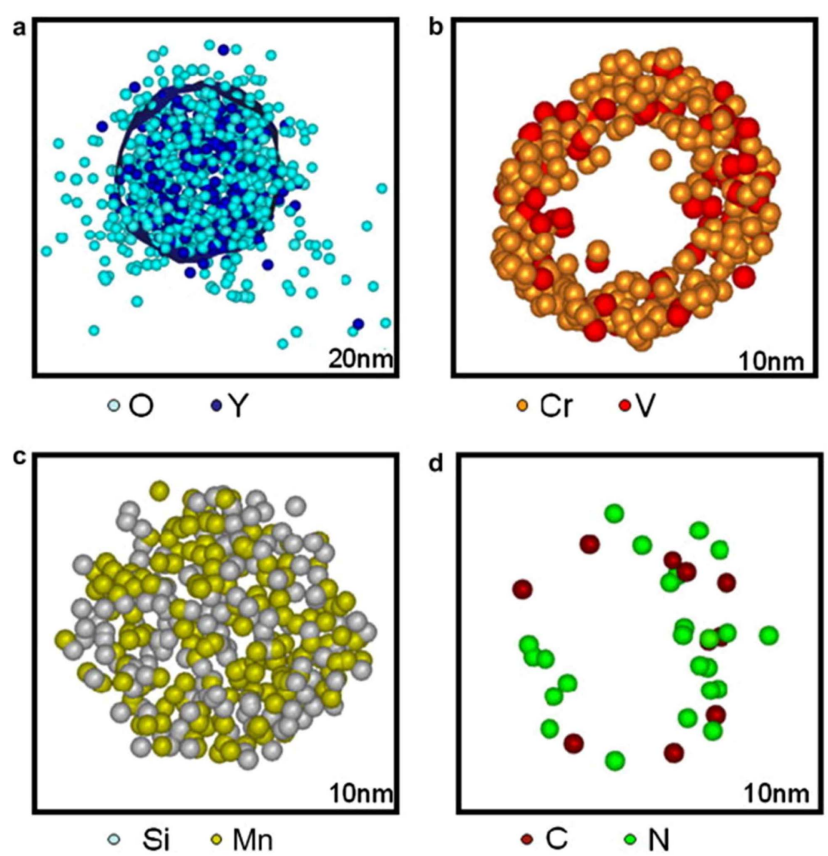

Fig. 5. Elemental distribution in an oxygen-rich cluster in the ODS-Eurofer 97 steel prepared by ball milling and hot isostatic pressure (obtained by Williams et al. [13]). Core-shell structure of the cluster is clearly visible. 

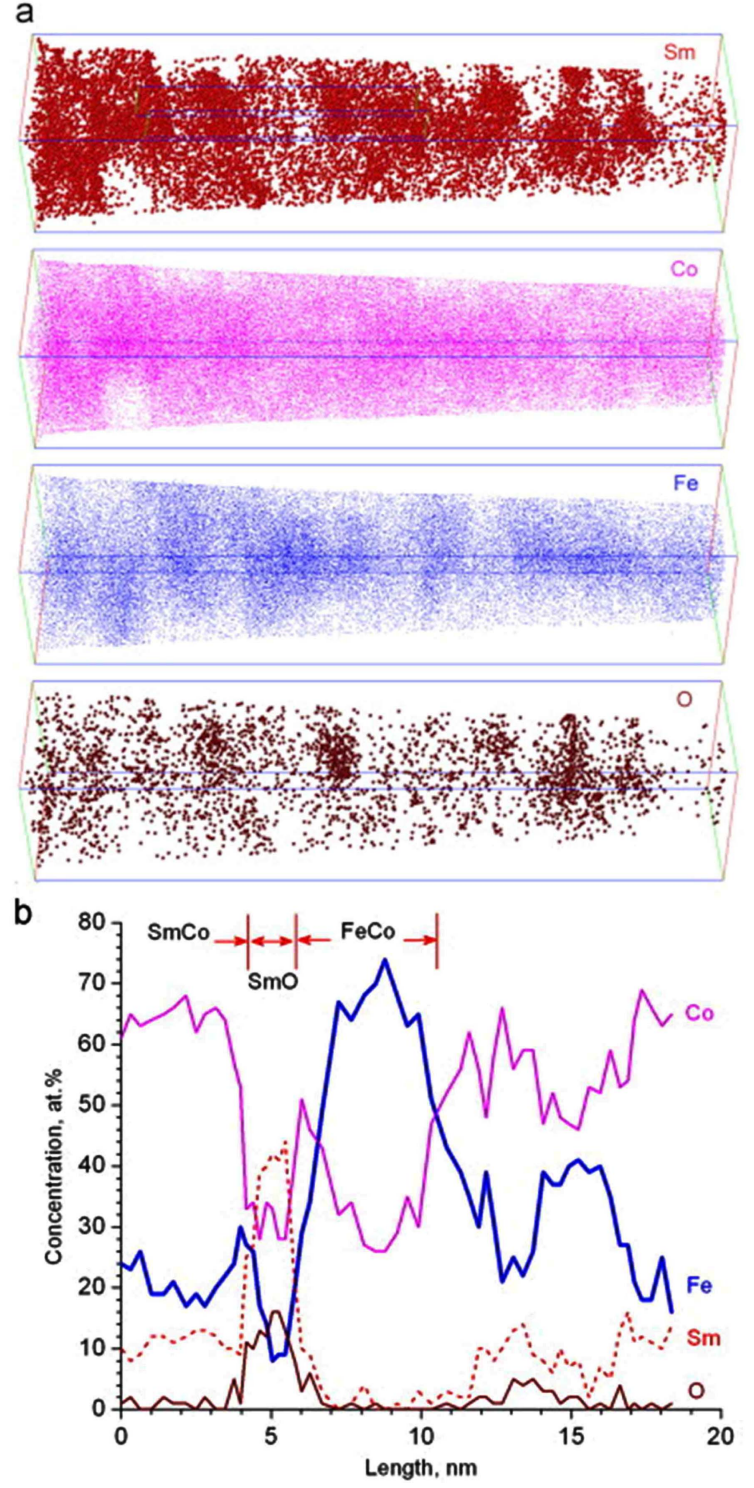

Fig. 6. Atom probe analysis of the nanocomposite $\mathrm{SmCo} / \mathrm{Fe}$ permanent magnet ((a) atom maps within the box of $10 \times 9 \times$ $46 \mathrm{~nm}^{3}$ size and composition profile and (b) composition profiles across iron-rich particle), taken from Xiong et al. [14].

compared to pure $\alpha-\mathrm{Fe}$ and, as a result, is responsible for beneficial magnetic properties of the nanocomposite material. The distribution of minor impurities which are detrimental to magnetic properties was also analyzed. The same compositional behavior was found in a similar $\mathrm{SmCo} / \mathrm{Fe}$ system by Le Breton et al. [15].

\section{Conclusions}

APT can provide useful and unique information on the local chemistry of powder materials. As examples, APT data on powder materials produced by mechanical alloy- ing (and subsequent sintering) were shown. Such studies not only give a deep insight into the atomic-scale elemental redistribution occurring under powder metallurgical processing but also a better understanding of the structure-property relationship of powder materials. Further development in specimen preparation techniques using FIB is expected to extend the application of APT to nanoparticle systems (e.g. catalysts and quantum dots). APT research on powder materials is just at its beginning and is expected to expand rapidly in the upcoming years.

\section{References}

[1] M. K. Miller and R. G. Forbes: Mater. Charact., 60 (2009) 461.

[2] M. K. Miller, Atom Probe Tomography - Analysis at the Atomic Level, Kluwer Academic/Plenum Publishers (2000) New York.

[3] T. Kelly, M. K. Miller: Rev. Sci. Instrum., 78 (2007) 031101.

[4] P. P. Choi, T. Al-Kassab, Y. S. Kwon, J. S. Kim and R. Kirchheim: Microsc. Microanal., 13 (2007) 347.

[5] P. P. Choi, Y. S. Kwon, J. S. Kim and T. Al-Kassab: J. Electronmicr., 56 (2007) 43.

[6] P. P. Choi, J. S. Kim, O. T. H. Nguyen and Y. S. Kwon: Mater. Letters, 61 (2007) 4591.

[7] C. Wille, T. Al-Kassab, M. Schmidt, P. P. Choi and Y. S. Kwon: Int. J. Mater. Res., 5 (2008) 541.

[8] C. Wille, T. Al-Kassab, P. P. Choi, Y. S. Kwon and R. Kirchheim: Ultramicroscopy, 109 (2009) 599.

[9] K. Thompson, D. Lawrence, D. J. Larson, J. D. Olson, T. F. Kelly and B. Gorman: Ultramicroscopy, 107 (2007) 131.

[10] E. P. Yelsukov, G. A. Dorofeev and A. L. Ulyanov: Chech J. Phys., 55 (2005) 920.

[11] C. Wille, T. Al-Kassab, P. P. Choi, Y. S. Kwon and R. Kirchheim: Ultramicroscopy, 109 (2009) 599.

[12] M. Brocq, B. Radiguet, J.-M. Le Breton, F. Cuvilly, P. Pareige and F. Legendre: Acta. Mater., 58 (2010) 1806.

[13] C. Williams, E. Marquis, A. Cerezo and G Smith: J. Nucl. Mater., 400 (2010) 37.

[14] X. Y. Xiong, C.B. Rong, S. Rubanov, Y. Zhang and J. P. Liu: J. Magn. Magn. Mater., 323 (2011) 2855.

[15] J. M. Le Breton, R. Larde, H. Chiron, V. Pop, D. Givord, O. Isnard and I. Chicinas: J. Phys. D: Appl. Phys., 43 (2010) 085001.

이 논문을 지난 30 여 년간 한국분말야금학회 발전 및 기술개발에 큰 업적을 남기신 울산대학교 권영순 교수님의 정년을 기념하여 헌정합니다. 